Orm

OAK RIDGE NATIONAL LABORATORY

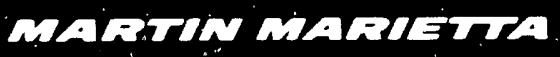

\section{Preliminary Engineering Studies for the Support Shell of the Outer Tracker of the SDC Detector}

David H. Vandergriff

September 1991 
This report has ben reproduced directly from the bast available copy

Available to DOE and DOE contractors from the Office of Scientific and Tectinical Information, P.O Box 62 Dak Ridge. TN 37831 , prices aveilabie trom (615) 576-8401, FTS 625-8404

Availabie to the public trom the National Technical Information Service, U.S Department of Commerce, 5285 Por Royal Rd. Springtield. VA 22161.

This report was preparen as an account of work sponsored by an agency of the United Siates Governmen: Neither the Unted States Government nor any azency thereot hor any of thet employges maxes any warranty, express or implied. or assumes an; ega lablity or responsibility for the accuracy. completeness. or usetulness of eny intormat: apparatus, projuct, or process dis. closed or represents that is use wow not iniringe privately owned rights. Reterence herein to any specitic commercal product. process. or service by trade name trademark man ulacturer or nerwise does not necessarily constfute or imply ts endorsement emmendation. or tavoring by the United States Government or any agen:y thereot. The views and opinions of authors expressed hereir. do not neckssarliy state or reflect those of the United States Government or any agency thereot 


\title{
Preliminary Engineering Studies for the Support Shell of the Outer Tracker of the SDC Detector
}

\author{
David H. Vandergriff \\ Engineering Division
}

September 1991

Contributing Author:

John Mayhall

Prepared by the

OAK RIDGE NATIONAL LABORATORY

Oak Ridge, Tennessee 37831

managed by

MARTIN MARIETTA ENERGY SYSTEMS, INC.

for the

U.S. DEPARTMENT OF ENERGY

under Contract No. DE-AC05-84OR21400 


\section{Table of Contents}

\section{Page}

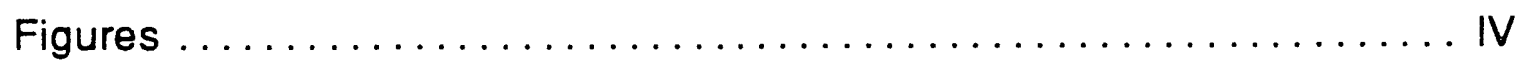

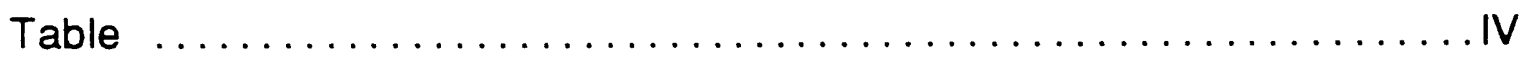

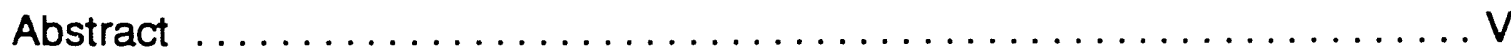

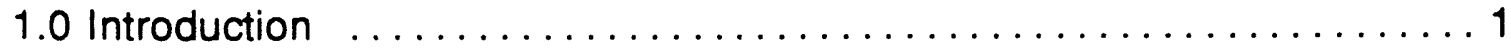

2.0 Support Shell Requirements $\ldots \ldots \ldots \ldots \ldots \ldots \ldots \ldots \ldots \ldots \ldots \ldots$

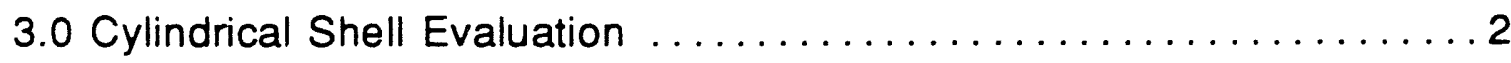

3.1 Shell Physical Analysis ..........................

3.2 Shell Cost Analysis ........................... 4

4.0 Modular shell Evaluation ........................... 8

4.1 Shell Physical Analysis ......................... 8

4.1.1 Buckling of Sides of Trough $\ldots \ldots \ldots \ldots \ldots \ldots \ldots$

4.1.2 Buckling of Lid Top ...................... 12

4.1.3 Bugling Due to Straw Pressure $\ldots \ldots \ldots \ldots \ldots \ldots 13$

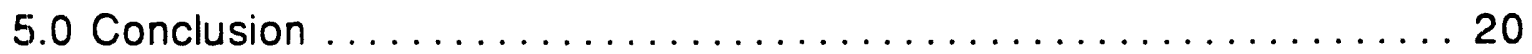




\section{FIGURES}

Figure

Page

1 Cylindrical Support Shell Tracking Element Arrangement........... 1

2 Modular Support Shell Tracking Element Arrangement............... 2

3 Structural Tube Typical Dimensions................................................... 3

4 NASTRAN Analysis Results................................................................ 5

5 MSC/CAASE Analysis Results............................................................. 5

6 Material Layup of Trough Sides....................................................... 11

7 Module Lid Top........................................................................................ 12

8 Straw Tracking Element Forces and Material Layup..................... 13

9 Straw Tracking Element Segment...................................................... 14

10 Lid Top Dimensions................................................................................... 17

\section{TABLE}

Table

1 First Unit Cylinder Fabrication Cost Estimate ................................ 7 


\begin{abstract}
The Solenoidal Detector Collaboration (SDC) detector is in the conceptual design phase. ORNL is currently working with various sub-groups on the design of the outer tracker portion of the SDC detector. A major focus in the outer tracker design is the structure that mounts and supports the tracking elements. This structure must meet extreme requirements of alignment and stability while containing a minimum of material. This report describes the requirements, evaluations, and analyses that have been performed on the two options being explored; a cylindrical support shell and a modular support shell.
\end{abstract}




\section{Preliminary Engineering Studies for the Support Shell of the Outer Tracker of the SDC Detector}

\subsection{Introduction}

The outer tracker of the Solenoidal Detector Collaboration (SDC) is in the initial phase of engineering design. Mechanical engineering of the outer tracker consists of mounting and supporting the straw tube (wire) and/or plastic scintillating fiber (PSF) tracking elements. The support and mount must provide an extremely stable platform onto which detector tracking elements are mounted. This platform must meet the requirements of precision alignment and location for the tracking elements. Various configurations of these elements have been proposed for use within the tracker design envelope. Preliminary studies of potential mounting schemes for these tracking elements have revealed two support shell options; the cylindrical support shell and the modular support shell. Engineering and physics studies of the outer tracker have provided the basis for the selection of the two options described in this report.

\subsection{Support Shell Requirements}

The support shell for the SDC outer tracker must provide a lightweight, low radiation length structure that is radiation hardened and is stable under thermal variations. Analysis has revealed that the location of the tracking elements must be known to 30 microns, 400 microns and 300 microns for circumferential, radial and longitudinal location, respectively. Two methods for achieving these goals are discussed here. The first method utilizes a precision cylinder with tracking elements placed directly on the cylinder's surface (Figure 1). Small modular support shells are used in the second method (Figure 2). Tracking elements are placed in the precision modular shells, which are then placed onto a less precise cylindrical support shell. Tolerances are met by placing the modules on precision machined rings which encircle the cylindrical support shell. Both methods are being evaluated to determine the feasibility of the designs.

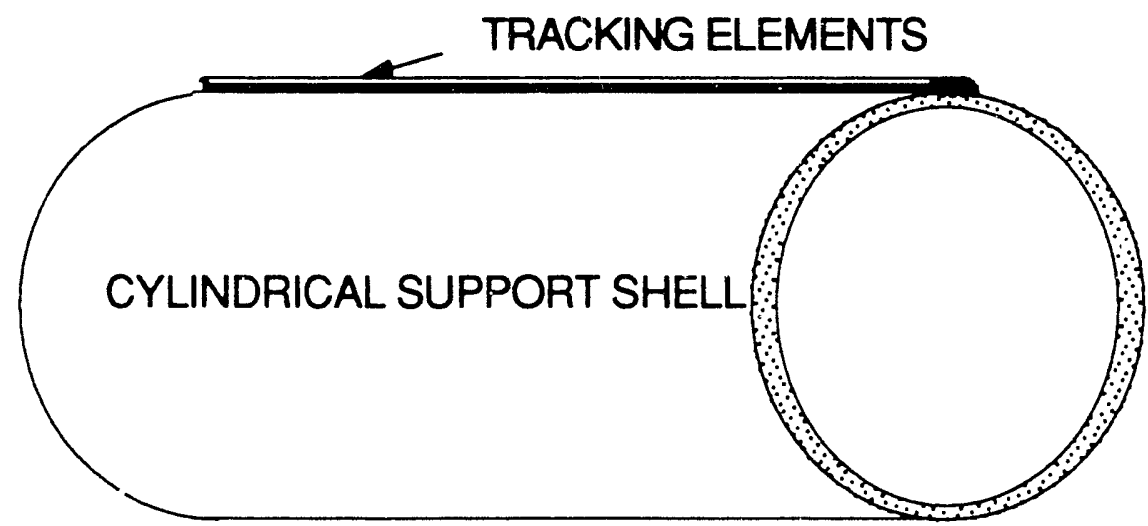

FIGURE 1 - Cylindrical Support Shell Tracking Element Arrangement 


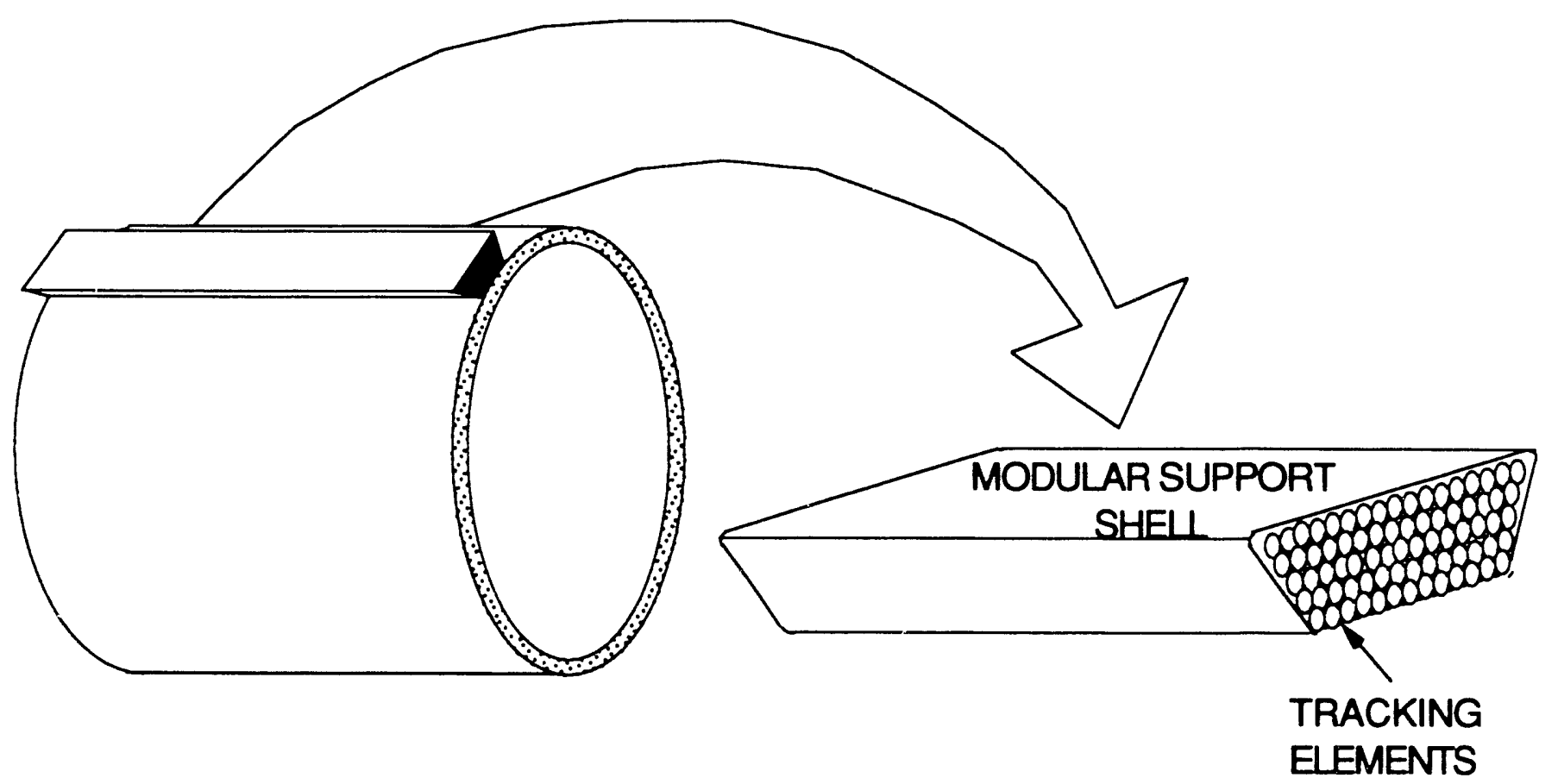

FIGURE 2 - Modular Support Shell Tracking Element Arrangement

\subsection{Cylindrical Shell Evaluation}

The outer tracker for the SDC detector requires a stable structure to mount the straw and fiber elements on. The use of a cylindrical shell fabricated from carbon composite based materials will provide this stable base. Analysis has been performed on both the physical properties of this structure and the cost for fabrication. The following sections detail the progress made in both endeavors.

\subsection{Shell Physical Analysis}

The cylindrical shell must provide a lightweight, low radiation length structure that is radiation hardened, and provides superior thermal stability. The cylinder must achieve the alignment requirements dictated by the physics. The alignment of each superlayer is simplified when each element can be registered from a common surface. This registration requires maximum stability under load. In addition th the requirements of the physics involved, the base structure must be simple to fabricate and assemble. The structural integrity of the cylindrical shell has been evaluated.

Cylinders used for the support of the tracking elements must exhibit minimum bending and deflection, and resist compression loading. Additionally, the cylinder design must prevent sag or local distortions. The ends of the cylindrical shell must have sufficient hoop strength to support the end plates, and finally, the carbon fibers used to make up the tube must be stable under varying environmental and physical loading conditions. 
The cylinder size chosen for assessment is based on the outer tracker description in the SDC Expression of Interest (EOI) document. An $80 \mathrm{~cm}$ radius cylinder, 6 meters long (Figure 3 ) is used. This cylinder is representative of the inner superlayer in the outer tracking volume of the Central Tracking Chamber (CTC). It is also the smallest cross section cylinder and therefore provides the most conservative results for the bending analysis. An initial cylinder thickness of $2.54 \mathrm{~cm}$ was chosen, based on the results of the standard beam deflection calculation shown below.

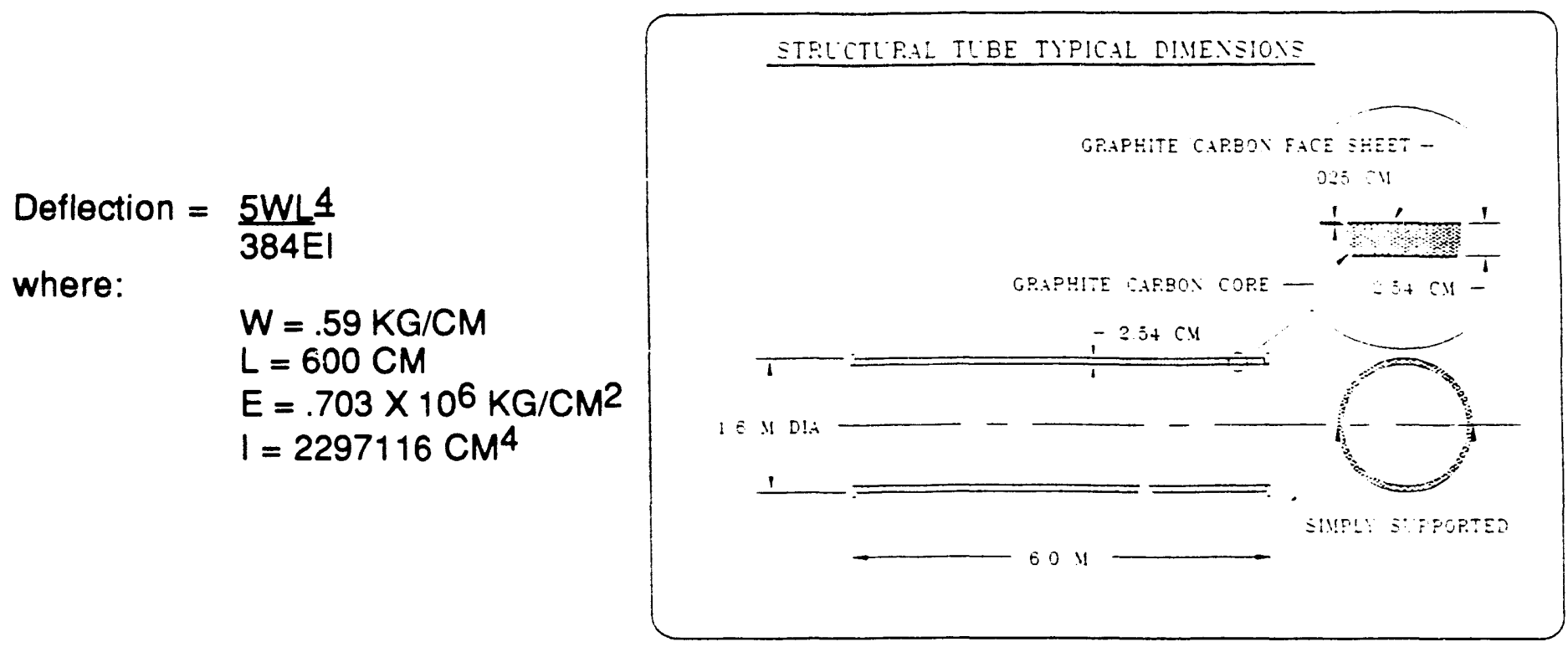

FIGURE 3 - Sructural Tube Typical Dimensions

This analysis assumes that the tube is simply supported, that the tube retains its circular cross section throughout its entire length, and that the $2.54 \mathrm{~cm}$ thickness is solid and has the modulus of elasticity of $10,000,000$ psi, a typical value for carbonbased materials. Based on these assumptions, the deflection was found to be less than 50 microns. This preliminary cylinder evaluation provides a basis for the in-depth finite element analyses that followed.

A series of finite element analyses (FEA) were done on the cylinder using models of increasingly more accurate and refined values for material properties and layup across the $2.54 \mathrm{~cm}$ thickness. The first FEA run duplicated the conditions described above, providing comparable results. This verified both the FEA model geometry as well as the hand calculations. Subsequent calculations lead to the final analysis presented here, based on the superlayer cross section described above.

The second FEA runs were performed on a cylinder with a "face sheet-core-face sheet" shell construction. This type of construction provides high bending stiffness with much lower mass than a solid cylinder. For analysis purposes, the material tensile modulus of the two carbon face sheets was set at $.7 \times 10^{6} \mathrm{KG} / \mathrm{CM}^{2}$. This 'alue was determined using the GENRAD composite material analyzer code. The program allows the user to input varying composite materials and layup orientations and receive material structural properties as output. 
Standard strength IM6 composite inaterial was chosen for the analysis. A wind pattern of $90 / 0 / 90$ was used to give a symmetric layup with the properties of a quasi-isotropic material. i.e., the same material properties in both the axial and transverse directions. This layup provides a structure that is structurally stable and resistant to distortions in thermal cycling conditions.

A carbon honeycomb core was used, based on the properties of the Hexcel Corporation HFT-G-3/16-6.0 Graphite Reinforced Honeycomb core. Any similar core material may be chosen because the analysis code, MSC/NASTRAN, ignores the bending properties of core material and only requires input of the shear modulus. The shear modulus included in this analysis is sufficiently low that it does not affect the results of the bending analysis and is representative of any number of core materials, including foam. Core material properties primarily affect the shear deflection of the struct: ire.

The FEA performed on the cylindrical shell was used to calculate the bending and sag properties only. Figure 4 displays the results of this analysis as performed on Nastran and post-processed using the PATRAN program. The FEA was verified using NASTRAN, NISA, and a PC-based analysis tool, MSC/CAASE (Figure 5). An additional check was made using a baseline analysis of a face sheet-core-face sheet structure. The results of each method agreed, providing a high degree of confidence in the results obtained.

Based on the accumulated results of these analyses, the basic cylinder is sufficiently stable to be used with confidence as a support structure for the straw tube and scintillating fiber tracking elements. The low deflection and radiation length of the structure meet the design requirements for the outer tracker. Additional analyses will be performed to optimize the material sizing and further reduce the radiation lengths.

\subsection{Shell Cost Analysis}

Recent evaluation of the cylinders used to support the tracking components of the outer tracker has centered around fabrication methods, and the cost associated with cylinder production. The basic assumptions for the stable base cylinder are: full length continuous cylinders; .015" to .020" wall thickness; graphite fiber reinforced epoxy composite; integral end rings with, possibly, intermediate stiffeners; and cylinder support from the ends only. An attempt has been made to produce an accurate cost analysis of the cylinders using these criteria and the dimensions provided for the "baseline" tracker design.

Many cost drivers will affect the estimate for fabrication of the required cylinders. The two principle drivers are cylinder size and required precision. Secondary variables are important, however, because performance requirements could elevate any of them to major importance. A few comments about the secondary variables are in order before discussing the cost estimate in terms of size and precision. 


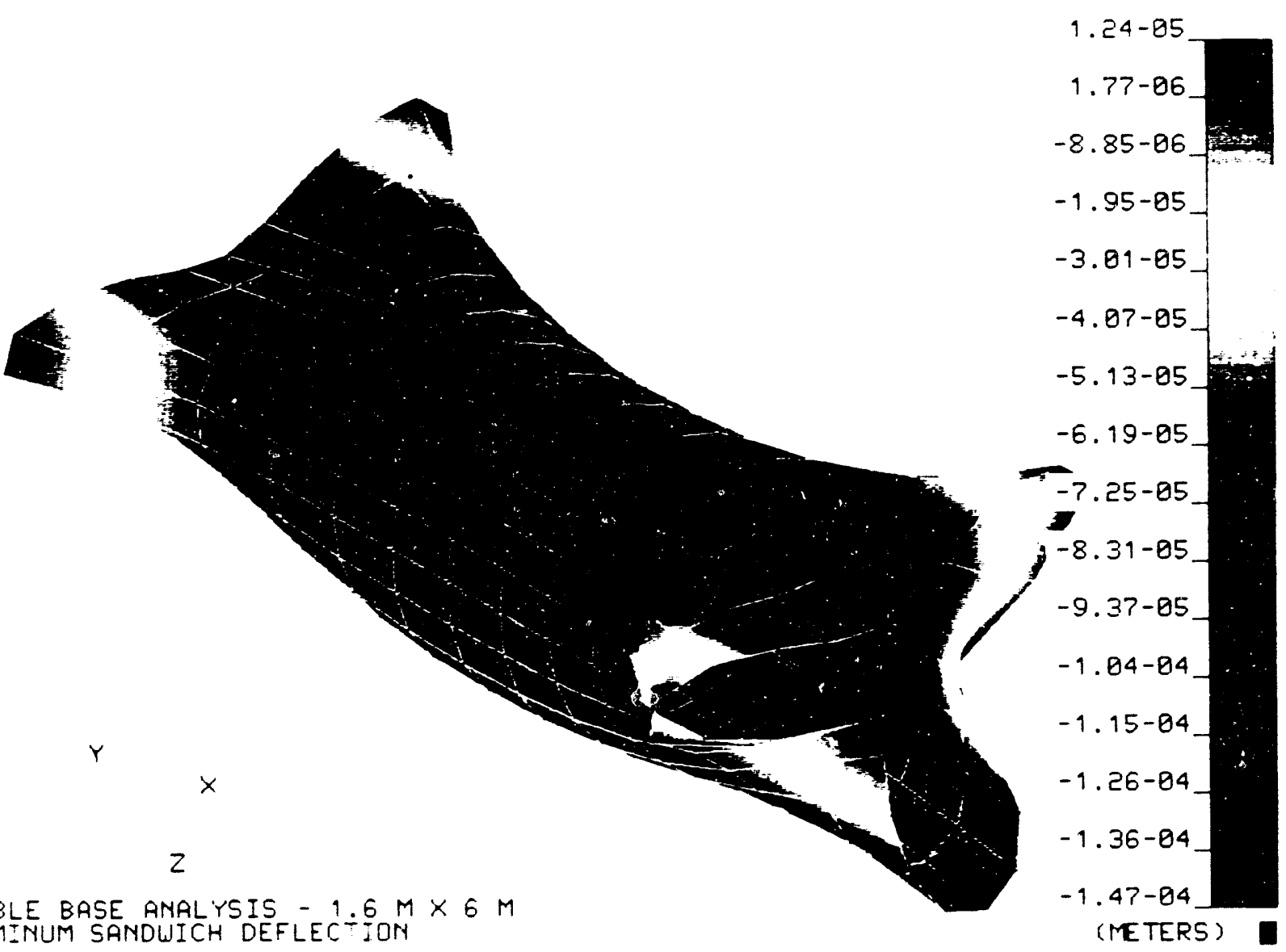

STABLE BRSE ANALYSIS - 1.6 M
GLUMINUM SANDLICH DEFLEC ION

FIGURE 4 - NASTRAN Analysis Results

Module f-1: Single Syan Beams Uinder Pransverse and Axial Loads

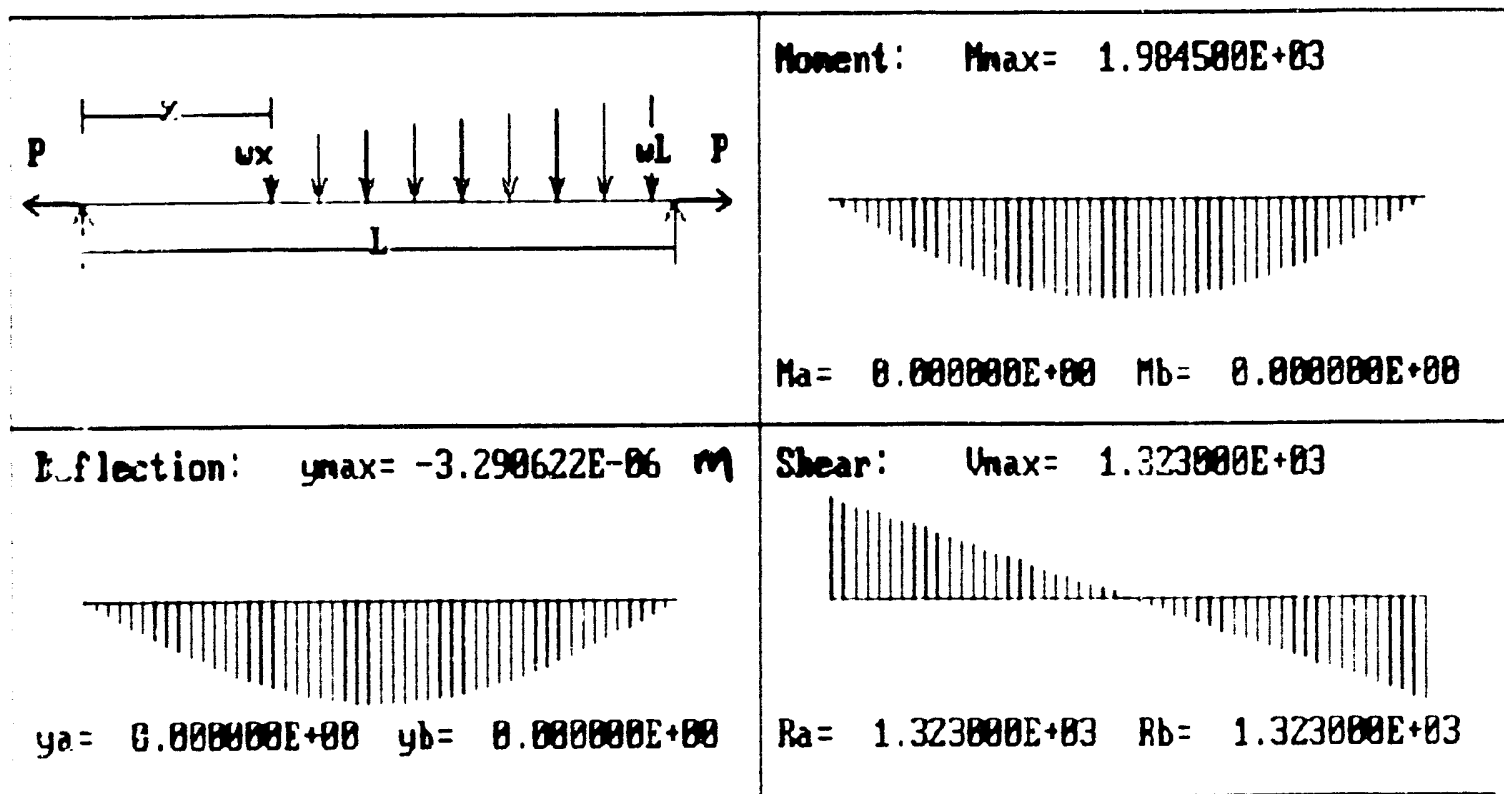

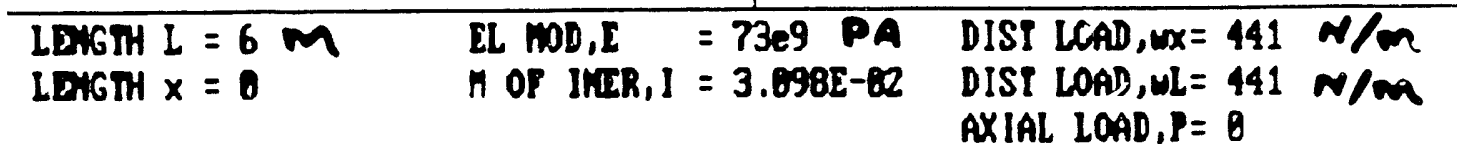

FIGURE 5 - MSC/CAASE Analysis Results 
The graphite fiber reinforced epoxy composite material has been chosen because it has a high specific strength and stiffness, low weight, and the material is expected to have a small influence on the performance of the detector. There are unknowns associated with this material: dimensional stability as a result of temperature changes or viscoelastic creep, and long term effects of the operational radiation environment.

Within the graphite/epoxy composite itself, the assumption is that the fiber modulus requirement will be less than $55 \mathrm{msi}$. This assumption is based on preliminary analysis of the strength requirements of the cylinder. Higher modulus fibers are readily available, but these tend to have very low strength and are difficult to use in high precision fabrication environments. Fibers which are both high in strength and modulus are available for special applications, and will be used if required.

The cylinder wall construction is assumed to be a wet wound, three layer 90/0/90 wall of $.005^{\prime \prime}$ material providing a total thickness of $.015^{\mathrm{n}}$. Additional evaluation and analysis must be performed to determine if this construction will meet mechanical design requirements. If thickness must be increased or the construction method modified, the effect of the presence of the cylinder on detector performance will become increasingly important. The relative effect of another construction method on the cost will be measurable but not a significant driver at this time.

A cost estimate for the first cylinder is presented in terms of cylinder O.D. and required precision (cylindricity) in Table 1. The estimates include the cost of a fabrication mandrel, winding attachments, and cylinder production tooling. Estimates do not include generic tooling such as the winding machine, cranes or other necessary handling equipment. The finished cylinder length has been set at 5 meters for this cost analysis. Mandrels are assumed to be chrome plated steel. The estimate is based upon informal discussion with mandrel suppliers, winding technology facilities, and potential fabricators. Previous experience at ORNL also was used in the estimates.

The cost estimates are also driven by some hidden considerations. The state of the ant in this technology is not advanced sufficiently to build all possibilities without incurring $R$ \& $D$ charges. These additional costs are contained in the estimates for the large diameter, high precision cylinders ( the lower left quadrant of the table). Conversely, the smaller, less precise cylinders in the upper right quadrant can be produced by several manufacturers without difficulty. Between these regions, there is an increasing amount of sophistication and capability required. For the baseline design, the smaller cylinders will be used for the fiber technology, which requires greater precision for mounting. The larger cylinders will be used for straw tracking which does not require the degree of precision necessary for the fibers. The fiber cylinders would have cylindricity requirements in the $.005 "$ range, and the straw cylinders in the $.010 "$ range.

Further evaluation is required to determine the final structural requirements of the cylinder. These requirements will feed directly into the cost estimate and physics performance capabilities of the tracker. These evaluations will continue in concert with the continued refinement of the straw tube and fiber tracking technologies, which will be mounted to the cylinders. 


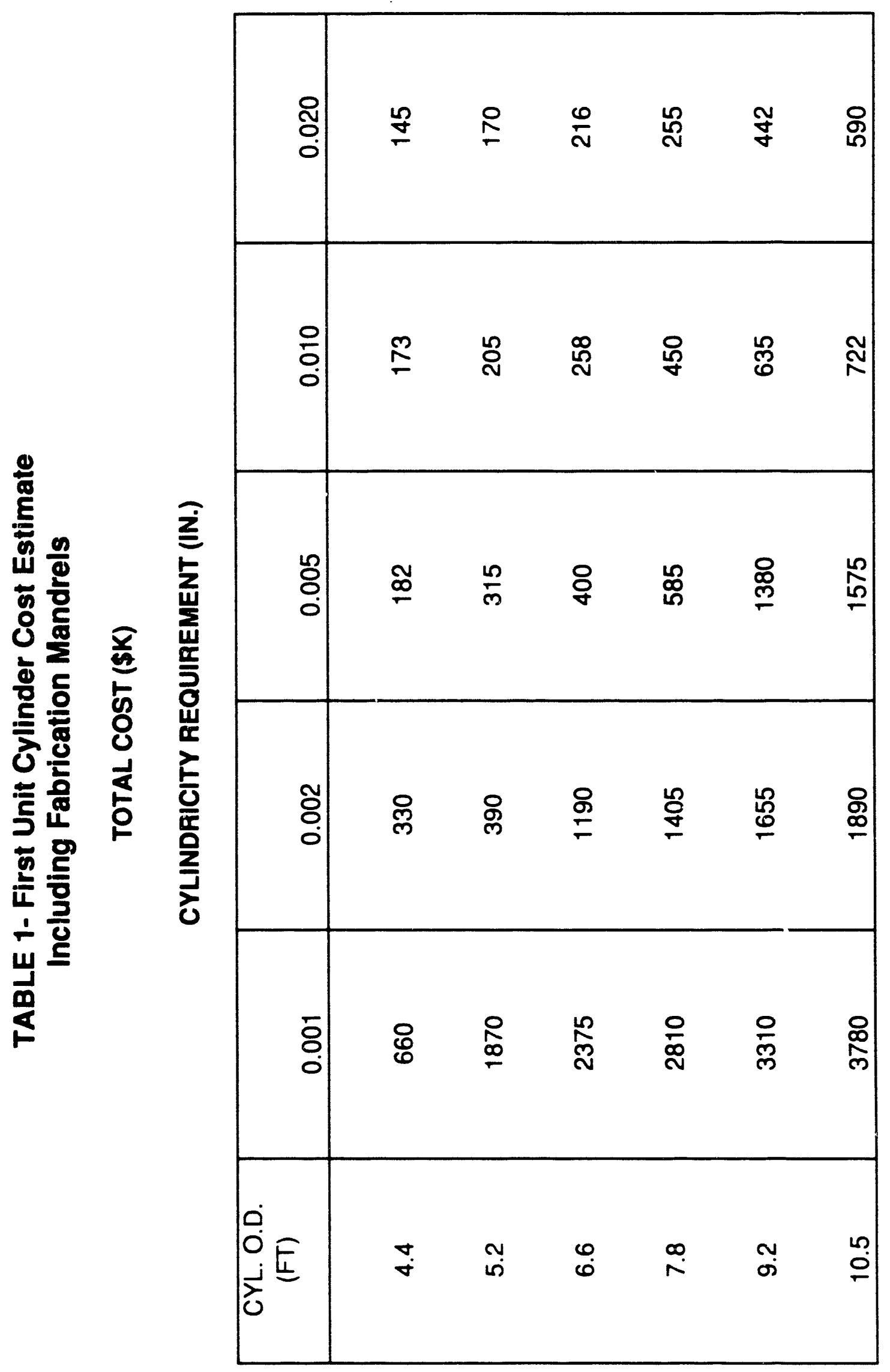




\subsection{Modular Shell Evaluation}

The modular shell design for the outer tracker of the SDC provides a method for holding the straw tracking elements in position and maintaining their alignment along the length of the module. The modules will be constructed of carbon-based composites and will span a length equal to half the overall outer tracker length. They will be supported along this length at approximately $80 \mathrm{~cm}$ intervals. The modules will be attached to a cylindrical shell similar to the one described above, which will provide the overall structural integrity of the system. The modular design provides for testing of individual unirs prior to assembly into an overall tracking unit. This report contains the results of the physical analysis of the shell as well as specifications for the fabrication of a prototypical modular she!l.

\subsection{Shell Physical Analysis}

The modular shell is designed to the same basic requirements as the cylindrical shell. This includes bending loads, compression loads and thermal loads. Additionally, due to the small size of the modular shell, thermal stresses are incurred in the manufacture of the shell that require special provisions to prevent distortion of the shell. The nature of these loads, the stresses that they produce, and the material layup required to negate them have been evaluated.

The thermal loads that result when a modular shell is cured and then returned to room temperature determine the design of the modular shell. The stress-free temperature of a cured composite is close to the maximum cure temperature at which most of the cross-linking occurs in the polymer used for the matrix. Due to the high coefficient of thermal expansion (CTE) of the epoxy and the negative CTE of the graphite, compressive buckling stress are induced in the graphite filament.

The induced compressive stresses in the thin laminates due to cooling from cure result in various modes of buckling, causing warping and waviness of the modules. To resolve this problem, a design consisting of a face sheet-core-face sheet layup was contrived. This design, using a foam core, saves weight over that of the solid laminate for the case of designing to prevent buckling due to compressive loads. This layup requires three layers of .0015 inch graphite on each side of the foam core. This layup, as in the case of the cylindrical shell, provides a balanced and symmetric structure capable of resisting physical loads and fabrication loads.

There are two types of residual stresses, shearing residual stresses between plies and between epoxy matrix and graphite filament. The residual stresses between plies are due to each ply of the laminate being differently oriented (e.g., $\pm 30^{\circ}$ layup), which causes each ply to have different coefficients of thermal expansion in different directions. These differences induce shearing forces between plies and cause warpage if the layup is not balanced and symmetric about the centroidal center line of the layup. If balanced and symmetric, however, the forces sum to zero and generally cause no trouble. Additionally, these stresses can be determined using finite-element laminated analysis, using the maximum curing temperature as zero stress 
temperature, and cooling back to room temperature, and reading out the resulting residual stresses.

The residual stresses between epoxy matrix and graphite filament are due to the enormous differences between graphite filament COE (coefficient of thermal expansion) and the epoxy COE. Again, these stresses do not cause warpage, providing the layup is symmetric and balanced about the centroidal plane. These stresses cannot be determined by laminated finite-element analysis. One would need to perform a "micro-finite-element" analysis, modeling individual elements of epoxy and elements of graphite in order to determine these stresses. These stresses can cause buckling of thin elements because of the net compressive forces which they produce in the graphite filaments. The following example can aid in this understanding. The current layup is as follows:

$[0 /+30 /-30 /-30 /+30 / 0] .0025 "$ per ply. The properties of this layup have been determined by finite element analysis to be:

$$
\begin{aligned}
& E_{0}=20.0(10)^{6} \mathrm{psi} \\
& E_{90}=2.14(10)^{6} \mathrm{psi} \\
& G=5.29(10)^{6} \mathrm{psi} \\
& \mathrm{COE}=\alpha \\
& \alpha_{0}=\frac{-1.382(10)^{6}}{{ }^{\circ} \mathrm{F}} \\
& \alpha_{90}=\frac{6.315(10)^{-6}}{{ }^{\circ} \mathrm{F}}
\end{aligned}
$$

If the layout is treated as two bars for an approximate analysis, one bar is graphite with a COE of $\alpha_{0}$ and the other will be epoxy with a COE of

$$
\frac{210(10)^{-6}}{{ }^{\circ} \mathrm{F}}, \alpha_{\theta} \text {. }
$$

The equation that expresses the behavior of the two bars during cooling is as follows:

$$
\Delta T\left(\alpha_{\theta}-\alpha_{0}\right)=\frac{P}{A_{\theta} E_{g}}+\frac{P}{A_{\theta} E_{\theta}}
$$


Where

$\Delta T=$ Cure Temperature - Room Temperature

$P=$ induced compressive force in graphite, equal to tensile for ce in epoxy

$A_{\theta}=$ cross sectional area of graphite

$A_{e}=$ cross sectional area of epoxy

$$
\left(\mathrm{A}_{\mathrm{\theta}}=.60 ; \mathrm{A}_{\mathrm{\theta}}=.40\right)
$$

$E_{g}=$ Modulus of graphite $=E_{0}=20(10)^{6}$

$E_{e}=$ Modulus of epoxy $=10(10)^{6} \mathrm{psi}$

However, the shear behavior will induce a force of $P$ (Equation 1). To determine the compressive stresses in the graphite, using Equation 1:

$$
\begin{aligned}
10^{-6}(350-70)[210-(-1.382)]= & {\left[\frac{1}{.4(10)^{6}}+\frac{1}{.6(20)}\right.} \\
\text { or } P=2426 \mathrm{lb} & \begin{aligned}
\text { Compressive Stress in Graphite } & =\frac{P}{A_{b}}=\frac{-2426}{.6} \\
& =-4043 \mathrm{psi}
\end{aligned}
\end{aligned}
$$

The equation

$$
\frac{P}{A_{\theta}} \approx \Delta T \quad 14.0
$$

will give a good estimate of the compressive stresses (that tend to buckle) induced in the curing $\Delta T$. Obviously, we would like $\Delta T$ to be as low as possible.

Such residual compressive stresses would be no problem in thick laminates or in supported thin laminates; i.e., thin face sheets bonded to honeycomb or foam sandwich.

Thus, buckling or crippling can occur during cure.

\subsubsection{Buckling of Sides of Trough}

From Timoshenko's Iheory of Elastic Stability, 1st Edition, 1936, page 339,

$$
\sigma_{a}=\frac{K \pi^{2} D}{b^{2} h}
$$


Where

$K=.456+\left(\frac{b}{a}\right)^{2}=.456+\left(\frac{1.403}{39.37}\right)^{2}=.457$

$D=! \sqrt{\left(E_{0} E_{90}\right)}$

1 = Bending moment of Inertia of cross section per running inch.

For our 6-ply [0/30/-30]s, layup,

$\mathrm{h}=.015$ in ; thickness

$a=39.37$ in; length

$\mathrm{b}=1.403 \mathrm{in} ;$ width

$I=\frac{(.015)^{3}}{12}=2.81(10)^{-7} \frac{\mathrm{in}^{4}}{\mathrm{in}}$

and $E_{0}$ and $E_{90}$ are the flexural moduli in the $0^{\circ}$ direction $\left[20(10)^{6}\right.$ psi] and $90^{\circ}$ direction $\left[2.14(10)^{6}\right.$ psi], respectively.

Thus from Equation 2:

$\sigma_{c}=\frac{.457 \pi^{2} \sqrt{20(2.14)} 10^{6}(2.81) 10^{-7}}{(1.403)^{2}(.015)}=281 \mathrm{psi}$

Since the residual compressive stress is $4043 \mathrm{psi}$, the side will buckle. An alternative design is:

$$
\begin{aligned}
& I=(.005)\left(\frac{h^{\prime}}{2}\right)^{2} 2+\frac{(.005)^{3}}{6}=.0025 h^{2}+2.08(10)^{-7}=.0025\left[h^{\prime 2}+8.33(10)^{-6}\right] \\
& E_{0}=19.8(10)^{6} \mathrm{psi} \\
& E_{90}=3.5(10)^{6}
\end{aligned}
$$

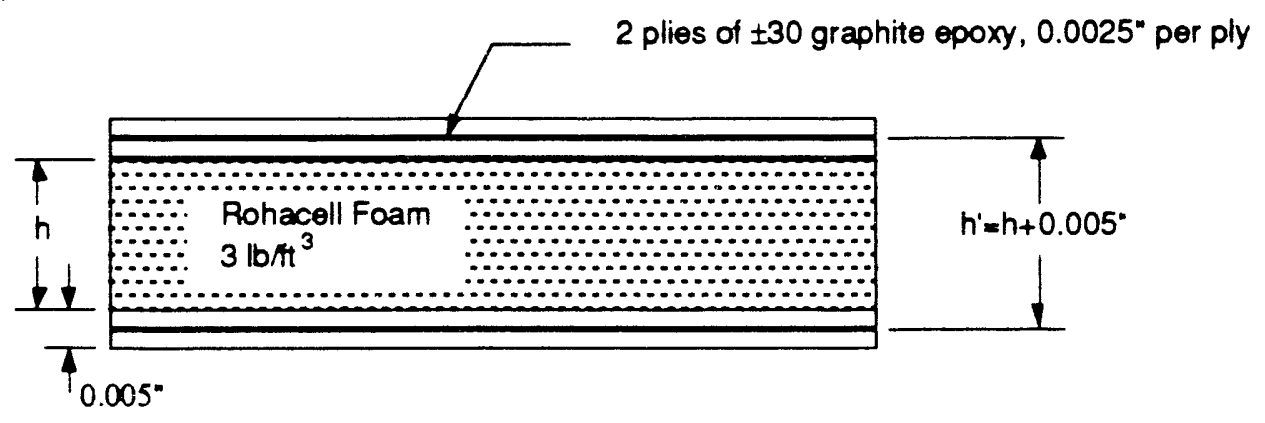

FIGURE 6 - Material Layup of Trough Sides 
Solve for $h$ ' required to give factor of safety of 2.

$$
\begin{aligned}
& 2(4043)=\frac{.457 \pi^{2} \sqrt{19.8(3.5)} 10^{6}(.0025)\left[h^{\prime 2}+8.33(10)^{-6}\right]}{(1.403)^{2}(.010)} \\
& h^{\prime}=.0411 \\
& h=.0411-.005=.0361
\end{aligned}
$$

Rohacell's thinnest foam is $1 \mathrm{~mm}$, or .0394 -in. This material is sufficient.

4.1.2. Buckling of LID TOP

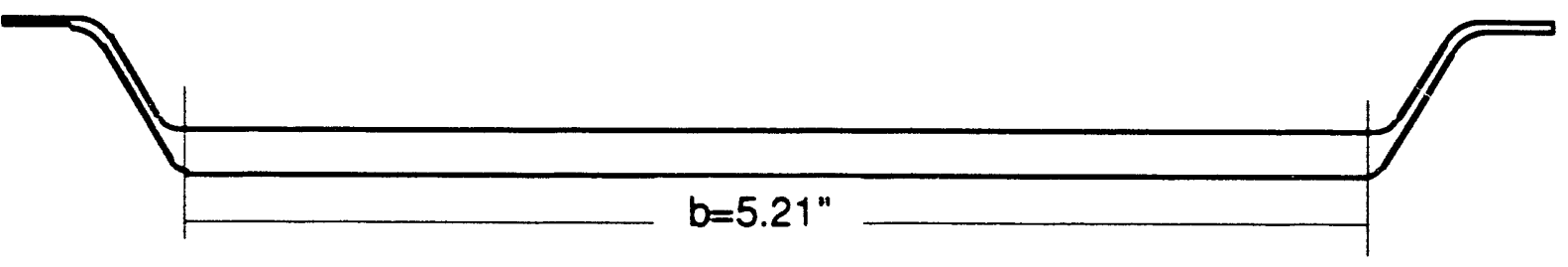

FIGURE 7 - Module Lid Top

Treated as a plate, a inches long, $b$ inches wide, simply supported all around, with axial compressive stresses of 4043 psi (page 10), using Timoshenko reference, page 329 , eqn. $213, \mathrm{~K}=4$.

$$
\sigma_{\sigma}=\frac{\left(N_{x}\right)_{a}}{h}=\frac{4 \pi^{2} D}{b^{2} h}
$$

or

$$
\sigma_{\sigma}=\frac{4 \pi^{2} \sqrt{E_{0} E_{90}} h^{3}}{b^{2} h 12}=\frac{\pi^{2} \sqrt{E_{0} E_{90}}}{3}\left(\frac{h}{b}\right)^{2}
$$

for the solution described,

$$
\sigma_{c}=\frac{\pi^{2}}{3} \sqrt{20(2.14)} 10^{6}\left(\frac{.015}{5.21}\right)^{2}=178 \mathrm{psi}
$$


With a residual compressive stress of $4043 \mathrm{psi}$, the plate will buckle. For the design using $l=.0025\left[h^{\prime^{2}}+8.33(10)^{-6}\right]$ and with the layup [30/-30/foam/-30/30] .0025 in. per ply, at a cure temperature of $200^{\circ} \mathrm{F}$, a stress $(\sigma=14 \Delta \mathrm{T})$ of $-1820 \mathrm{psi}$ is developed. Determine the foam thickness required to prevent buckling. Equation 2 becomes:

$2(1820)=\frac{4 \pi^{2} \sqrt{19.8(3.5)}(.0025)\left[h^{\prime^{2}}+8.33(10)^{-6}\right] 10^{6}}{(5.21)^{2}(.010)}$

or $h^{h^{2}}+8.333(10)^{-6}=.0012026$

$h^{\prime}=.0346$

$\mathrm{h}=.0296$

Thus .030 -in foam would be required to prevent this buckling.

\subsubsection{Bulging Due to Straw Pressure}

The module lid top and trough bottom will squeeze the straws together. They will be squeezed down against the wire supports, which are spaced every $80 \mathrm{~cm}$ (31.5"). While clamped in this squeeze, the lid will be bonded onto the trough. Because of compliance of the straw, it will exert pressure back against the lid and trough after removal from the bonding fixture, causing bulging, analyzed as follows:
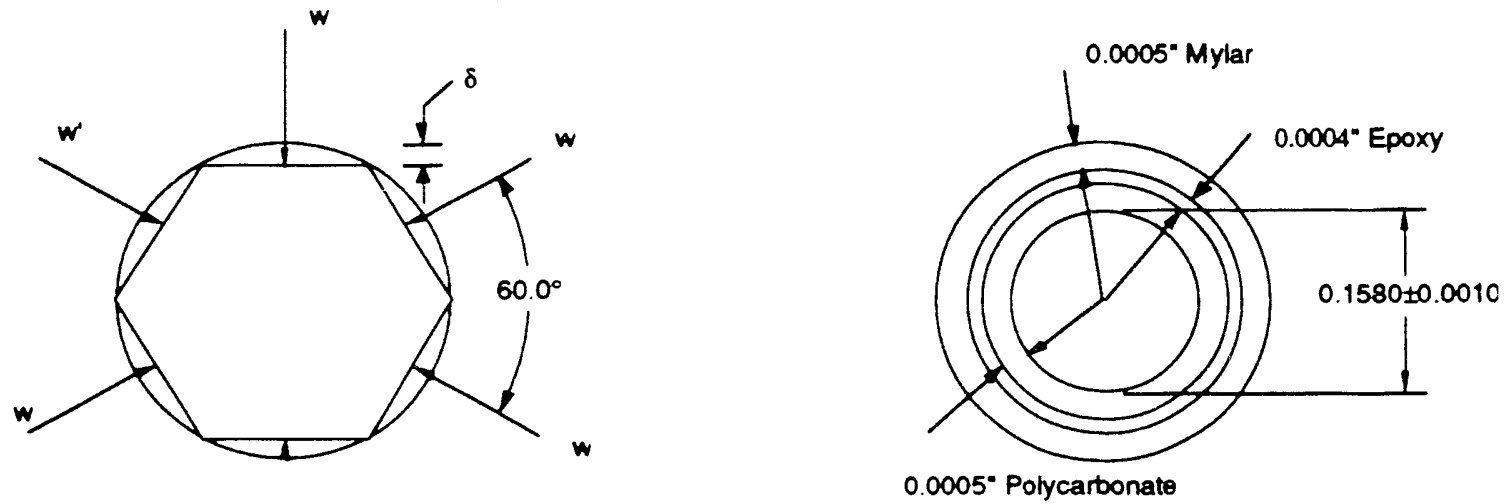

FIGURE 8 - Straw Tracking Element Forces and Material Layup

The force $W$ (applied on 6 sides) can be determined versus deflection, $\delta$ from Roark, 5th Edition, page 226, case 7 as follows: 
$\delta=\frac{W R^{3}}{E I}\left[\frac{1}{4 \sin ^{2} \theta}\left(\theta K_{1}+\frac{\sin ^{2} \theta}{2} K_{3}\right)-\frac{1}{2 \theta}\right]$

Equation 4

The properties of the straw materials are as follows:

Material

Specific Gravity

Young's Modulus, psi

Ultimate Strength, psi

Elongation, \%

CTE
Mylar

.920
25,000
1,500
--
$\frac{90(10)^{-6}}{{ }^{\circ} \mathrm{F}}$

Epoxy

1.35

200,000

5,000

$-$

$\frac{30(10)^{-6}}{{ }^{\circ} \mathrm{F}}$

\section{Polycarbonate}

1.20

330,000

9,000

100

$\frac{37.5(10)^{-6}}{{ }^{\circ} \mathrm{F}}$

Determine $\mathrm{El}$ of Wall of straw in bending for a 1 " section

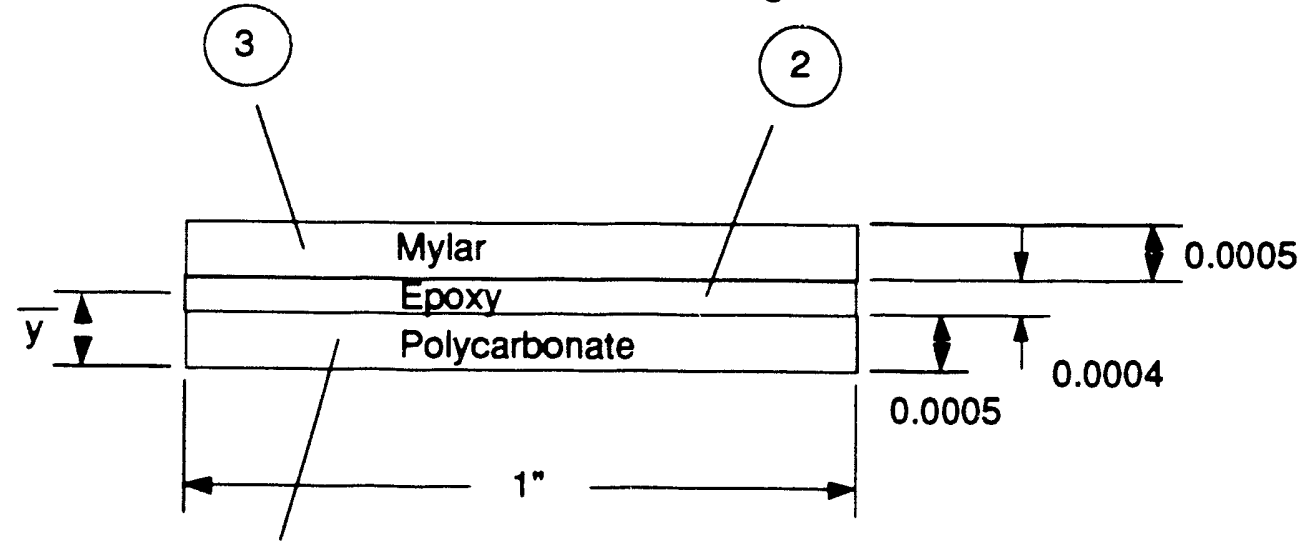

1

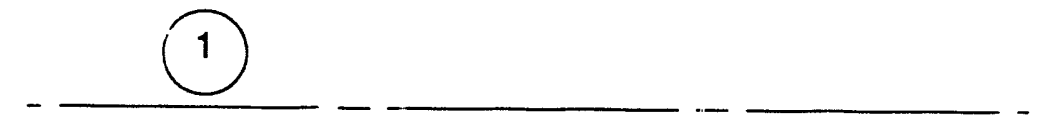

FIGURE 9 - Straw Tracking Element Segment

\begin{tabular}{|c|c|c|c|c|c|c|c|}
\hline \multirow{3}{*}{$\begin{array}{c}E \\
330,000 \\
200,000 \\
25,000\end{array}$} & Item & A & EA & y & EyA & $E \bar{y}^{2} A$ & El \\
\hline & $\begin{array}{l}1 \\
2 \\
3\end{array}$ & $\begin{array}{l}.0005 \\
.0004 \\
.0005\end{array}$ & $\begin{array}{l}165.0 \\
80.000 \\
12.50\end{array}$ & $\begin{array}{l}.00025 \\
.0007 \\
.00115\end{array}$ & $\begin{array}{l}.04125 \\
.0560 \\
014375\end{array}$ & $\begin{array}{l}.0000103125 \\
.0000392 \\
0000: 653125\end{array}$ & $\begin{array}{l}3.4375(10)^{-6} \\
1.0666(10)^{-6} \\
260417(101-6\end{array}$ \\
\hline & & & 257.5 & & .111625 & $6.604(10)^{-5}$ & $4.7646(10)^{-6}$ \\
\hline
\end{tabular}




$$
\begin{aligned}
& Y=\frac{\Sigma E \bar{A} A}{\Sigma E A}=.0004335 ; \\
& R=\frac{.1580}{2}+\bar{y} ; \text { or } \\
& R=.07943^{\prime \prime} \\
& E T=\Sigma E T+\Sigma \bar{y}^{2} A E-(\text { EEA }) \bar{y}^{2} \\
& E T=2.242(10)^{-5} \mathrm{lb}-\mathrm{in}^{2}
\end{aligned}
$$

Equation 4 becomes as follows:

$$
\begin{aligned}
& \theta=30^{\circ} \\
& \alpha=\frac{1}{A R^{2}}=\frac{2.242(10)^{-5}}{257.5(.07943)^{2}}=138(10)^{-5} ; K_{1}=1 \\
& \beta=\frac{F E I}{G A R^{2}} \tilde{=} \frac{1.5(2.242) 10^{-5}}{\left[10^{5}(1.4)(.07943)^{2}\right]}=3.8(10)^{-8} ; K_{3}=1.0 \\
& \delta=W \frac{(.07943)^{3}}{2.242(10)^{-5}}\left[\frac{1}{4 \sin ^{2} 30^{\circ}}\left(\frac{\pi}{6}+\frac{\sin 60}{2}\right)-\frac{1}{\frac{\pi}{3}}\right]=.0376 \mathrm{~W}-\text { in } \\
& W=K \delta=25.6 \delta \\
& \text { Where } K=\text { constant of straw. }
\end{aligned}
$$

Amount that straw will be squeezed $\delta=.00160=\frac{.1590-.1558}{2}$

Pressure on shell of Module due to straw squeeze will be $\mathrm{q} \mathrm{lb} / \mathrm{in}^{2}$

$$
q=\frac{W}{\text { strawpitch }}=\frac{26.6(.00160)}{[.1558+.0014(2)]}=.268 \mathrm{psi}
$$

First jetermine bulge of $4 \mathrm{ply},( \pm 30)_{s}$, without foam, and then with foam:

Roark, 5th Edition, pg. 386, case 1a, 


$$
\begin{aligned}
& \frac{a}{b}=\frac{315}{5.21}=6.05 \\
& \Delta_{b}=\frac{\alpha q b^{4}}{E_{90} t^{3}} 5 \\
& E=E_{90}=3.51(10)^{6} \\
& \alpha=.142 \\
& \Delta_{b}=\frac{.142(.268)(5.21)^{4}}{3.51(10)^{6}(.010)^{3}}=7.97-\text { in }
\end{aligned}
$$

This does not provide adequate stiffness. Assume the following:

$\Delta_{b}=(7 \sin 60+1) \delta$ for 8 rows of straws.

So, when $\delta=.0016, \Delta_{b}$ should be less than $(7 \sin 60+1) .0016=.0113$ To assure that this condition is met,

Replace $t$ in Equation 3 with $t^{*}$, where

$$
\begin{aligned}
& \frac{\left(\mathrm{t}^{*}\right)^{3}}{12}=\frac{\mathrm{h}^{\prime^{2}}(.010)}{4} \\
& \mathrm{t}^{*^{3}}=.030 \mathrm{~h}^{2} \\
& \Delta_{\mathrm{b}}=.0113=\frac{.142(.268)(5.21)^{4}}{3.51(10)^{6}(.030) \mathrm{h}^{\prime 2}} \\
& \mathrm{~h}^{\prime}=.1535 \mathrm{in}
\end{aligned}
$$

0.154 -in of foam reduces the flexibility by a factor of $7.99 / .0113$ or 707 . (over 700 times as stiff as without the foam).

The use of $1.9 \mathrm{lb} / \mathrm{tt}^{3}$ Rohacell WF Grade, .150 in thick foam increases the stiffness and weighs only as much as 1.07 plies of graphite epoxy. The transverse flexibility problem of the sides, top and bottom is solved by placing 0.015 -in. foam in the sides of trough and 0.150 -in of foam in the bottom and top of the module.

Instability due to one side of the trougil or lid buckling before the other side does presents the final obstacle. We will first check the lid for this phenomenon. 
Check the lid for twist-bend buckling. See appendix (see J.F'. Den Hartog's Advanced Strength of Materials, page 283) for explanation of this buckling mode.

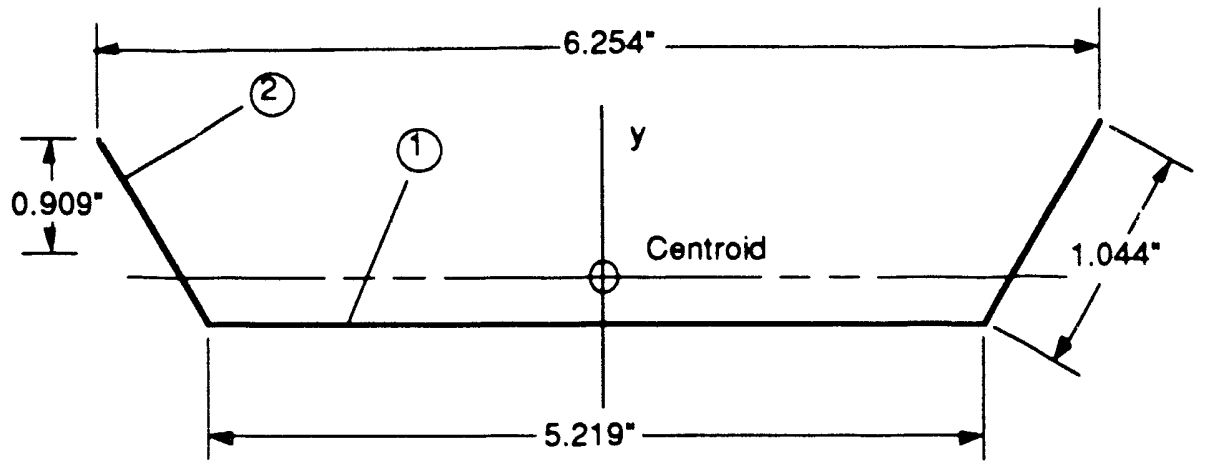

FIGURE 10 - Lid Top Dimiensions

From the appendix, $M_{0} \equiv M_{0}$, where

$M_{0}=\frac{\pi \sqrt{E I_{f} \cdot C}}{1}$

$\begin{array}{lccccc}\text { Item } & \mathrm{A} & \bar{y} & \mathrm{~A} \bar{y} & A \bar{y}^{2} & 1 \\ \text { Trough } & .0521 & .005 & 2.605(10)^{-4} & 1.3025(10)^{-6} & 4.3417(10)^{-7} \\ \text { Lid } & .02088 & .452 & .0094378 & .0042659 & .0014218 \\ & & & .0096983 & .0042672 & .0014222\end{array}$

analyzed for $[ \pm 30]_{s} .0025 \mathrm{in} / \mathrm{ply}$

$$
\begin{aligned}
A & =.07298 \\
\bar{y} & =.13289 \mathrm{in} \\
\mathrm{If} & =.0014222+.0042672-.0096983(.13289) \\
& =.00440 \mathrm{in}^{4}
\end{aligned}
$$

$C \theta=T$; or twist angle per in of length $=\frac{\theta}{L}=\frac{T}{C}$

See Roark, 5th Edition, page 300, case 1., C=KG 


$$
\begin{aligned}
& K=\frac{t^{3}}{3}(h+2 b)=\frac{(.010)^{3}}{3}[5.21+2(.904)]=2.34(10)^{-6} \\
& G \text { of }[ \pm 30]_{8} \text { layup }=6.39(10)^{6} \\
& \therefore C=K G=14.95 \mathrm{in}^{2}-\mathrm{lb}
\end{aligned}
$$

Equation 4 becomes:

$$
\begin{aligned}
& M_{0}=\frac{\pi}{32^{\prime \prime}} \sqrt{20(10)^{6}(.00440) 14.95} \\
& M_{0}=112.6 \mathrm{in}-\mathrm{lb}
\end{aligned}
$$

What differential stress and strain in the turned-up legs would produce this buckling moment:?

Determine $I_{y y^{\prime}}$ from Figure above

$$
\begin{aligned}
& \mathrm{I}_{y y}=.010 \frac{(5.21)^{3}}{12}+(1.044)(.010) 2(2.866)^{2}=.289 \mathrm{in}^{4} \\
& \sigma=\frac{M_{0} C}{\mathrm{I}}=\frac{(112.6) 2.87}{.289}=1,118 \mathrm{psi} \\
& \text { Strain }=E=\frac{\sigma}{E}=\frac{1118}{20(10)^{6}}=.0000559 \frac{\mathrm{in}}{\mathrm{in}}
\end{aligned}
$$

Now, we should estimate what possible differential stress exists in the cured graphite epoxy.

Cured Graphite Epoxy Cools from $350^{\circ} \mathrm{F}$ to $70^{\circ} \mathrm{F}$

$$
\begin{aligned}
& E_{\text {epoxy }}=1(10)^{6} \mathrm{psi} \\
& E_{\text {graphite }}=60(10)^{6} \mathrm{psi} \\
& \Delta_{\theta}-\Delta_{\theta}=P_{A}\left[\frac{1}{A_{\theta} E_{\theta}}+\frac{1}{A_{\theta} E_{\theta}}\right] \\
& P_{A}=\left(\frac{\Delta_{E}-\Delta_{\theta}}{\frac{1}{A_{\theta} E_{\theta}}+\frac{1}{A_{\theta} E_{\theta}}}\right)=\frac{(25+1.38) 10^{-8}(-280)}{\left[\frac{1}{.40(10)^{6}}+\frac{1}{.60(60) 10^{6}}\right]} \\
& P_{.4}=-2922 \mathrm{lb} \\
& \text { stressin graphite }=\frac{P_{A O}}{.60}=\sigma_{\theta} \\
& \sigma_{\theta}{ }^{4}=-4,870 \text { psicompression }
\end{aligned}
$$


Differential Stress in Flanges $=\sigma^{5}{ }_{\theta}-\sigma^{4}{ }_{\theta}=-2395$ psi

Also note that if one flange buckled before the other, twist-bend buckle would occur. The -2395 psi is more than twice the value required to buckle the lid in twist-bend.

Will foam will solve the twist-bend buckling problem?

To determine $\mathrm{K}(\mathrm{C}=\mathrm{GK})$; use Roark, 5th Edition, a combination of case 1 (pg. 300) and case 16 (pg. 293):

Treat the case as two springs in parallel

$$
\begin{aligned}
& (T=K G \theta) \\
& T_{1}+T_{2}=T \\
& T_{T}=G K_{T}=G\left(K_{1}+K_{2}\right) \\
& K_{T}=K_{1}+K_{2} \\
& K_{1}=\frac{(.010)^{3}}{3} \cdot 2(.904)+\frac{(.005)^{3}(5.21) 2}{3} \\
& \text { or } K_{1}=6.027(10)^{-7}+4.342(10)^{-7} \\
& K_{2}=\frac{2(.005)(5.125-.005)^{2}(.16-.005)^{2}}{(5.125+.160-.010)}=1.19394(10)^{-3} \\
& K_{T}=K_{1}+K_{2}=1.1945(10)^{-3} \\
& G=6.39(10)^{-6} \\
& C=G K_{T}=7630 \mathrm{in}^{2} / \mathrm{lb}
\end{aligned}
$$

If If were the same,

$$
\begin{aligned}
M_{0} & =\frac{\pi}{32} \sqrt{20(10)^{6} .00440(7,630)} \\
& =2544
\end{aligned}
$$

and the critical differential stress would be $\left(\sigma=\frac{M C}{1}\right) 25,300 \mathrm{psi}$

Thus, whereas the design without foam would buckle (twist bend) at a differential stress of only $1,118 \mathrm{psi}$, the design with .150-in of foam between the face sheets (of \pm 30 plies on each side), would require 25,300 psi differential stress. Thus, 0.150 -in of foam necessary for minimizing bulging will also eliminate twist-bend buckling. 
The results of this analysis indicate that 0.039 -in foam in side walls and 0.150 -in foam in the bottom and top of module (trough and lid) will prevent buckling and excessive bulging in the module.

\subsection{Conclusion}

Design and fabrication of support shells for the outer tracker of the SDC detector requires significant studies into the behavior of candidate materials and processes. The contradictory requirements of low mass, low deflection, and high thermal stability demand continued evaluations and development in the field of carbon-based composite materials. The results of studies of the cylindricai shell and modular shell are directly applicable to one another, and the two designs are progressing in a coordinated manner. This preliminary report presents the results of engineering studies conducted on the two shell configurations described above. The final results of this design task will be applicable to many additional fields requiring high precision, lightweight structures. The spin-off technologies from work on the Superconducting Super Collider project are only beginning to be realized. 
Intermal Distribution

$\begin{aligned} 1 . & \text { G. T. Alley } \\ 2 . & \text { C. M. Amonett } \\ 3 . & \text { B. R. Appleton } \\ 4-6 . & \text { H. G. Brashear } \\ 7 . & \text { D. D. Cannon } \\ 8 . & \text { F. C. Davis } \\ 9 . & \text { T. E. Douglass } \\ 10 . & \text { B. F. Elam } \\ 11 . & \text { C. P. Frew } \\ 12-15 . & \text { T. A. Gabriel } \\ 16-18 . & \text { C. A. Hall } \\ 12 . & \text { L. E. Johnson } \\ 13 . & \text { R. M. Leitch } \\ 14 . & \text { J. A. Mayhall } \\ 15 . & \text { F. A. Modine } \\ 16-20 . & \text { T. L. Ryan }\end{aligned}$

21. A. W. Trivelpiece

22. R. M. Tuft

23-26. D. H. Vandergriff

27. Plant Records

28. R. W. Brockett (Consultant)

29. J. J. Dorning (Consultant)

30. J. E. Leiss (Consultant)

31. N. Moray (Consultant)

32. M. F. Wheeler (Consultant)

33. EPMD Reports Office

34-35. Laboratory Records Department

36. Laboratory Records,

ORNL-RC

37. Document Reference Section

38. Central Research Library

39. ORNL Patent Section

\section{External Distribution}

40. Dr. John R. O'Fallon, Division of High Energy Plıysics, Department of Energy, ER-22/GTN, Washington, DC 20545

41. Office of Assistant Munager, Energy Research and Development, DOEORO, P. O. Box 2001, Oak Ridge, Tn 37831

42-52. Office of Scientific and Technical Information, Department of Energy, Oak Ridge, TN 37831

53. Muzzafer Atac, Fermi Niational Laboratory, P.O. Box 500, MS-233, V.H14NE, Batavia, Il 60510

54. William L. Dunn, Quantum Research Services, Inc., 100 Capicola Dr., Suite 109, Durham, NC 27713-4411

55. W. T. Ford, University of Colorado, Physics 390, Boulder, CO 80309-0390

56. M. G. D. Gilchriese, Law rence Berkeley Laboratory, One Cyclotron Road, MS-50A-2160, Berkeley, CA 94720

57. A. T. Goshaw, Duke Ur.iversity, Physics Dept., Durham, NC 27706

58. Gail Hanson, Indiana University, Physics Dept., Bloomington, N 47405

59. D. S. Koltick, Purd'se University, Physics Dept., West Lafayette, IN 47907

60. Haroid Ogren, Indiana University, Physics Dept., Bloomington, IN 47405

61. Seoz Oh, Duke University, Physics Dept., Durham, NC 27706

62. Stephen Reucroft, Northeastern University, Physics Dept., Boston, MA 02115

63. Randy Ruchti, University of Notre Dame, Physics Dept., Notre Dame, IN 46556

64. George Trilling, Lawrence Berkeley Laboratory, One Cyclotron Road, MS 50A-2160, Berkeley, CA 94720 

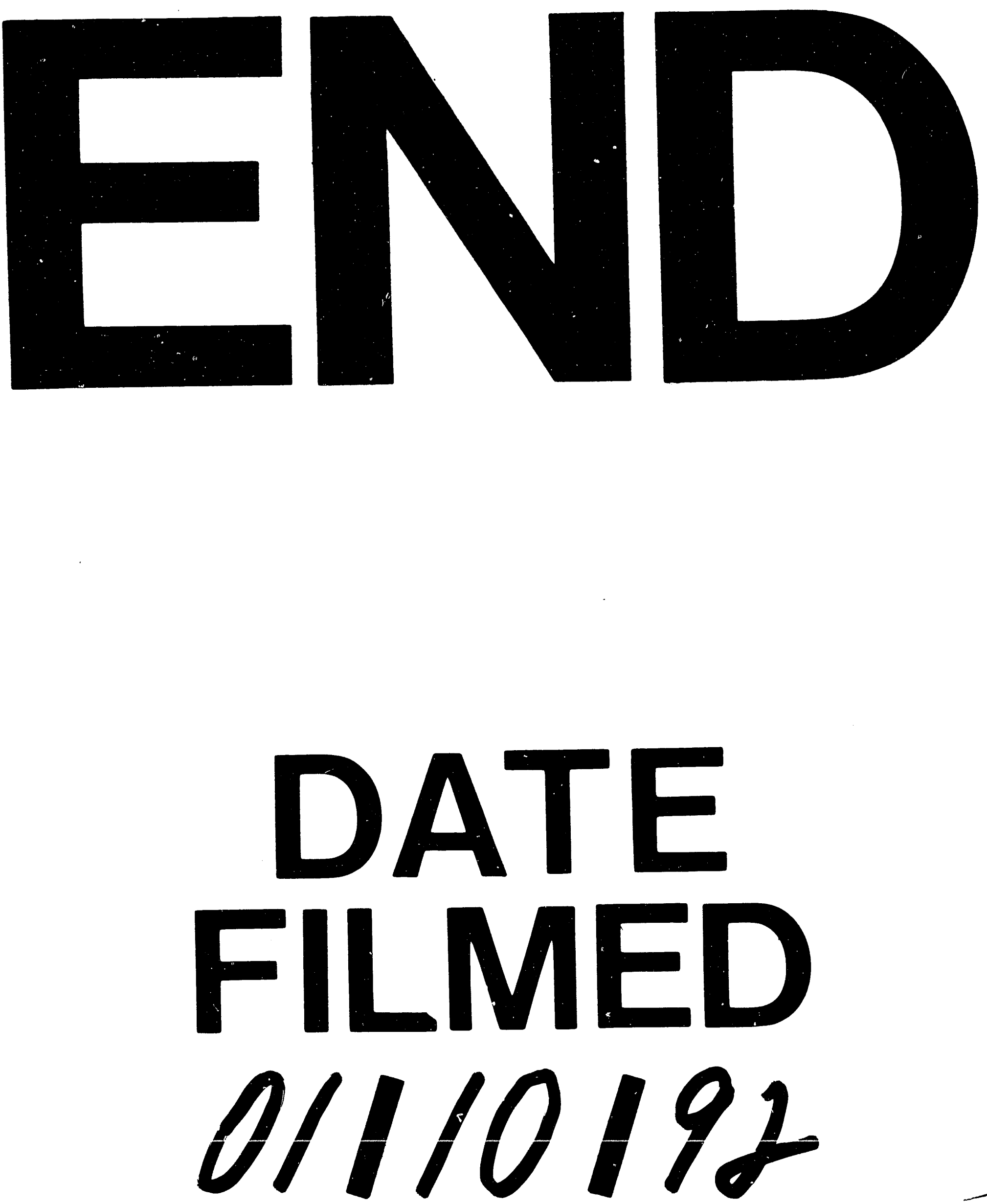
